\title{
Convalescent plasma therapy and remdesivir duo successfully salvaged an early liver transplant recipient with severe COVID-19 pneumonia
}

\author{
Imtiakum Jamir ${ }^{1}$, Pankaj Lohia ${ }^{1}$, Rajesh Kumar Pande ${ }^{2}$, \\ Rasika Setia ${ }^{3}$, Amit Kumar Singhal ${ }^{4}$, and Abhideep Chaudhary ${ }^{1}$ \\ Departments of ${ }^{1}$ HPB Surgery and Liver Transplantation, ${ }^{2}$ Critical Care, ${ }^{3}$ Transfusion Medicine, \\ ${ }^{4}$ Liver Transplant \& HPB Anaesthesia, B. L. Kapoor Super Speciality Hospital, New Delhi, India
}

\begin{abstract}
The impact and clinical spectrum of COVID-19 infection in liver transplant recipients/solid organ transplants are being unveiled during this recent pandemic. The clinical experience of use of current antiviral drugs and immunomodulators are sparse in solid organ transplantation. We present the clinical course of a 49-year-old male recipient who underwent living donor liver transplant for recurrent gastrointestinal bleed and contracted severe COVID-19 pneumonia during the third postoperative week. Herein we report the successful management of severe COVID-19 pneumonia using convalescent plasma therapy and remdesivir. Recipient's clinical deterioration was halted after three consecutive convalescent plasma transfusions with improvement in hypoxia and inflammatory markers (interleukin-6 and C-reactive protein). The use of convalescent plasma therapy along with remdesivir may be an ideal combination in the management of severe COVID-19 pneumonia in solid organ transplant recipients. (Ann Hepatobiliary Pancreat Surg 2020;24:526-532)
\end{abstract}

Key Words: COVID-19; Convalescent plasma therapy; Remdesivir; CRP; CRS; RT-PCR; Liver transplant

\section{INTRODUCTION}

India ranked third globally in COVID-19 cases as of July 2020. ${ }^{1}$ In India living donor liver transplant is offered as a predominant form of transplant service. The closure of transplant activities during the early months of the pandemic took a huge toll on patients awaiting liver transplant. The trepidation among transplant communities for subjecting the healthy donors and immune suppressed recipients to the risk of COVID-19 infection was legitimate. We rebooted our logistics and reconstructed our protocols to prevent the risk of COVID-19 illness as per national and international transplant society guidelines. ${ }^{2,3}$

The early report of COVID-19 related perioperative mortality of a liver transplant recipient from China highlights the severity of illness which one can encounter. ${ }^{4}$ Currently multiple clinical and randomized trials are underway to find effective combination therapy in severe
COVID-19 illness. The use of antiviral drugs and immunotherapy in transplant settings are limited to case reports. ${ }^{5,6}$ Herein we report a case of severe COVID-19 pneumonia in an early post liver transplant recipient managed with a combination of convalescent plasma therapy (CPT) and remdesivir.

\section{CASE}

A 49-year-old obese (BMI-33.9) Indian male, known case of ethanol related decompensated liver cirrhosis with recurrent life threatening variceal bleeds, mild ascites and jaundice (CTP score -9, Child: B, MELD Na: 17) was referred to us for liver transplant. He had no previous history of hypertension, diabetes, or asthma. His 45-year-old wife was evaluated for donation as per our unit protocol. The first nasopharyngeal swab for COVID-19 reverse transcriptase polymerase chain reaction (RT-PCR) test

Received: August 28, 2020; Revised: September 14, 2020; Accepted: September 20, 2020

Corresponding author: Imtiakum Jamir

Department of HPB Surgery and Liver Transplantation, B. L. Kapoor Super Speciality Hospital, Pusa Road, Rajendra Place, New Delhi 110005, India

Tel: +91-7835056106, Fax: +91-11-25752885, E-mail: dr.imtiakumjamir@gmail.com

Copyright (C) 2020 by The Korean Association of Hepato-Biliary-Pancreatic Surgery

This is an Open Access article distributed under the terms of the Creative Commons Attribution Non-Commercial License (http://creativecommons.org/ licenses/by-nc/4.0) which permits unrestricted non-commercial use, distribution, and reproduction in any medium, provided the original work is properly cited. Annals of Hepato-Biliary-Pancreatic Surgery - pISSN: 2508-5778 - elSSN: 2508-5859 
was taken at initial visit and subsequently two swabs were taken 48 hours apart prior to planned surgery which were negative for both the donor and recipient. After taking informed consent for the potential risk of nosocomial COVID-19, we conducted a live donor liver transplant with a partial MHV (Middle hepatic vein) right lobe graft and splenic artery ligation on $23^{\text {rd }}$ June 2020. Splenic artery ligation was done for portal inflow modulation in view of low graft to recipient weight ratio (GRWR-0.70, right graft weight-635 gms) and intraoperative high portal pressure $(16 \mathrm{mmHg})$. His intraoperative course was uneventful and was extubated on post-operative day one (POD1).

Post-operative doppler of the recipient showed high portal blood flows $(2000 \mathrm{ml} / \mathrm{min}, 315 \mathrm{ml} / \mathrm{min} / 100 \mathrm{gm})$ which was pharmacologically modulated with octreotide infusion during the $1^{\text {st }}$ post-operative week. As per our unit protocol for partial liver graft, he was given intra- venous methylprednisolone $10 \mathrm{mg} / \mathrm{kg}$ during the anhepatic phase following which it was rapidly tapered to $100 \mathrm{mg}$ (POD1), $80 \mathrm{mg}$ (POD2), $60 \mathrm{mg}$ (POD3), $40 \mathrm{mg}$ (POD4) and thereafter was switched over to oral wysolone $20 \mathrm{mg}$ once daily from POD5. He was started on tacrolimus on POD2 $(0.05 \mathrm{mg} / \mathrm{kg}$ divided into twice daily dose) and subsequent dosages were adjusted as per tacrolimus trough level 8-10 ng/ml. Although we routinely start mycophenolate mofetil (MMF) during the $1^{\text {st }}$ post operative week in our unit, we were unable to do so in our patient due to his low platelet and total leucocyte counts. However, a low dose of MMF (250 mg/12 hr) was started on POD8 in view of his rising aminotransferases (Table 1, Fig. 1).

The serum aspartate aminotransferase (AST) and alanine aminotransferase (ALT) showed a rising trend in the $2^{\text {nd }}$ post-operative week and methylprednisolone pulse therapy was given to which he responded well (Fig. 1). A percutaneous liver biopsy was not performed in view

Table 1. Trends of selected blood counts in the post-operative period (mean and range)

\begin{tabular}{|c|c|c|c|c|c|c|}
\hline & 1st week & 2nd week & 3rd week & 4th week & 5 th week & 6 th \& 7th week \\
\hline Haemoglobin $(\mathrm{g} / \mathrm{dl})$ & $7.78(6.9-9.6)$ & $8.11(7.5-8.5)$ & $8.94(8.3-9.8)$ & $8.98(8.5-9.5)$ & $8.31(7.5-9.2)$ & $9.45(8.3-11.1)$ \\
\hline $\begin{array}{l}\text { Platelet }\left(\times 10^{3}\right. \\
\mu \text { itre })\end{array}$ & $41.28(23-59)$ & $31.14(28-32)$ & $50.43(40-69)$ & $52.43(46-65)$ & $65.71(33-97)$ & $153.75(112-194)$ \\
\hline $\begin{array}{l}\text { Total leucocyte } \\
\text { count }\left(\times 10^{3} \mu \text { itre }\right)\end{array}$ & $4.7(1.69-7.09)$ & $4.77(2.39-8.69)$ & $4.7(3.67-6.53)$ & $6.28(4.44-9.42)$ & $3.09(1.88-5.98)$ & $6.67(2.89-12.68)$ \\
\hline $\begin{array}{l}\text { Absolute } \\
\text { lymphocyte count } \\
\left(\times 10^{3} \mu \text { itre }\right)\end{array}$ & $0.24(0.11-0.35)$ & $0.11(0.08-0.14)$ & $0.14(0.1-0.16)$ & $0.31(0.18-0.46)$ & $0.22(0.12-0.45)$ & $0.58(0.2-1.43)$ \\
\hline
\end{tabular}

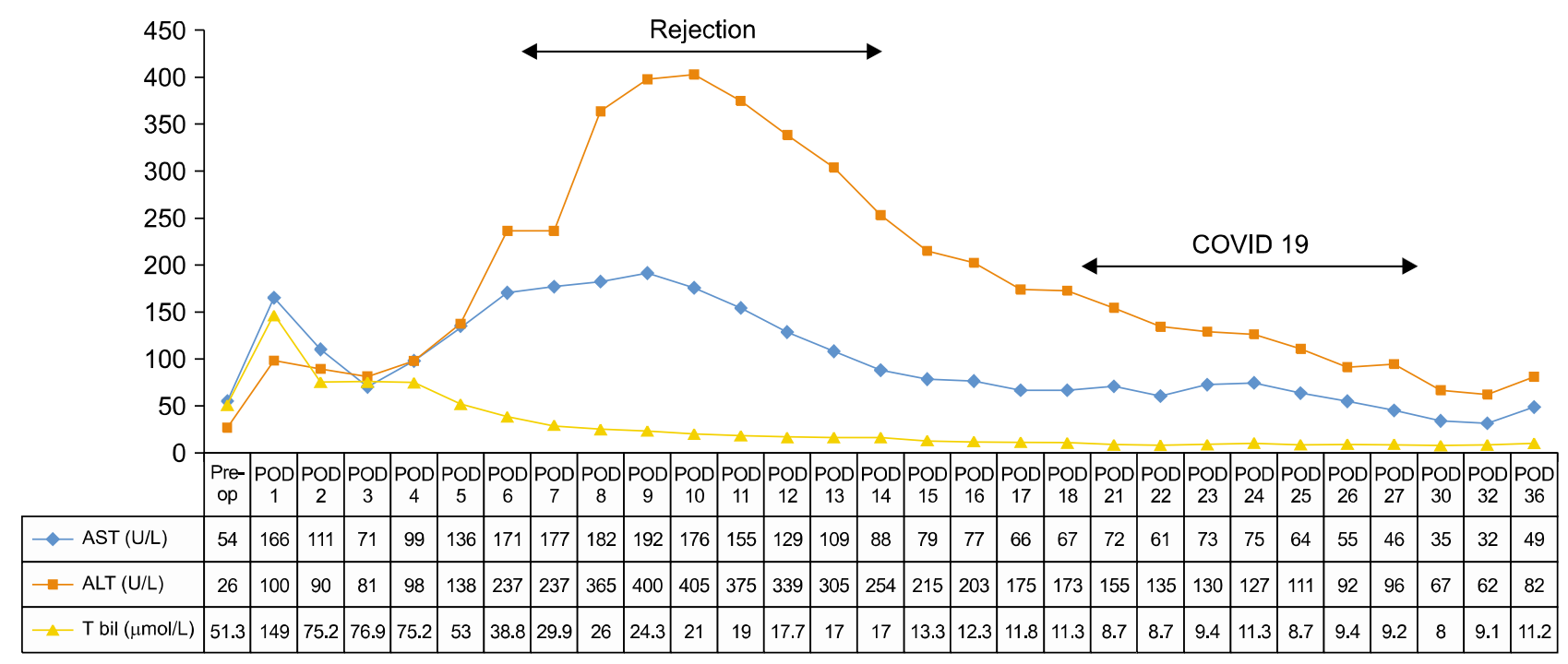

Fig. 1. AST, ALT and total bilirubin values during the hospital course. 
of the existing thrombocytopenia. The four fold rise of aminotransferases with absence of sepsis, normal doppler study and cirrhosis being ethanol related was highly suggestive of acute cellular rejection (ACR).

He had a satisfactory hospital course and was due for discharge on POD20 when he developed fever. His temperature was $101^{\circ} \mathrm{F}$, heart rate 110 per minute, respiratory rate 26 per minute with a drop in saturation to $88 \%$ on ambient air. On day 2 of fever the RT-PCR from nasopharyngeal swab detected the presence of severe acute respiratory syndrome coronavirus-2 (SARS-CoV-2). The patient's nasopharyngeal aspirate was negative for all other respiratory viruses confirmed with Rapid nucleic acid amplification testing (Bio Fire Film Array Respiratory Panel tests). His immunosuppression was modified, MMF was stopped, oral steroid was changed to intravenous hydrocortisone and tacrolimus in low dose was continued in view of recent recovery from acute rejection. His oxygen saturation was maintained between $94 \%$ and $96 \%$ with high-flow nasal cannula oxygen therapy (Fig. 2).

On day 3 of fever (POD22) he became increasingly tachypnoeic (respiratory rate-37/min) and chest x-ray showed patchy parenchymal bilateral opacities (Fig. 3).
He was pre-emptively shifted to intensive care isolation for possible need of invasive ventilation. Blood tests for inflammatory markers including interleukin-6 (IL-6), $\mathrm{C}$-reactive protein (CRP), N-terminal pro b-type natriuretic peptide (NT-proBNP), serum ferritin and septic screening were done. He was started on injection remdesivir $200 \mathrm{mg}$ on first day followed by $100 \mathrm{mg}$ once daily for the next five days. Subcutaneous enoxaparin 60 $\mathrm{mg}(0.6 \mathrm{ml})$ was given once daily and non-invasive ventilation was continued (Fig. 2). However, despite these measures there was a rapid clinical deterioration of his oxygenation (NIV $\mathrm{FiO}_{2}-0.5, \mathrm{SpO}_{2}-92 \%, \mathrm{PaO}_{2}-71 \mathrm{mmHg}$ and $\mathrm{PF}$ ratio-143) along with elevated inflammatory markers IL-6-74.65pg./dl, NT-ProBNP-1305 pg/dl and CRP-69.95 $\mathrm{mg} / \mathrm{dl}$ (Fig. 4). The mean lymphocyte count continued to remain less than $0.5 \times 10^{3}$ per microlitre till the $5^{\text {th }}$ postoperative week. HRCT chest could not be performed in view of orthopnoea, instead serial bed side x-rays were done (Fig. 3).

We decided against administration of tocilizumab, as thrombocytopenia continued to persist in the late post-operative weeks (Table 1). As our hospital was gradually gaining experience in treating sick COVID-19 patients

\section{Fever}

Fever
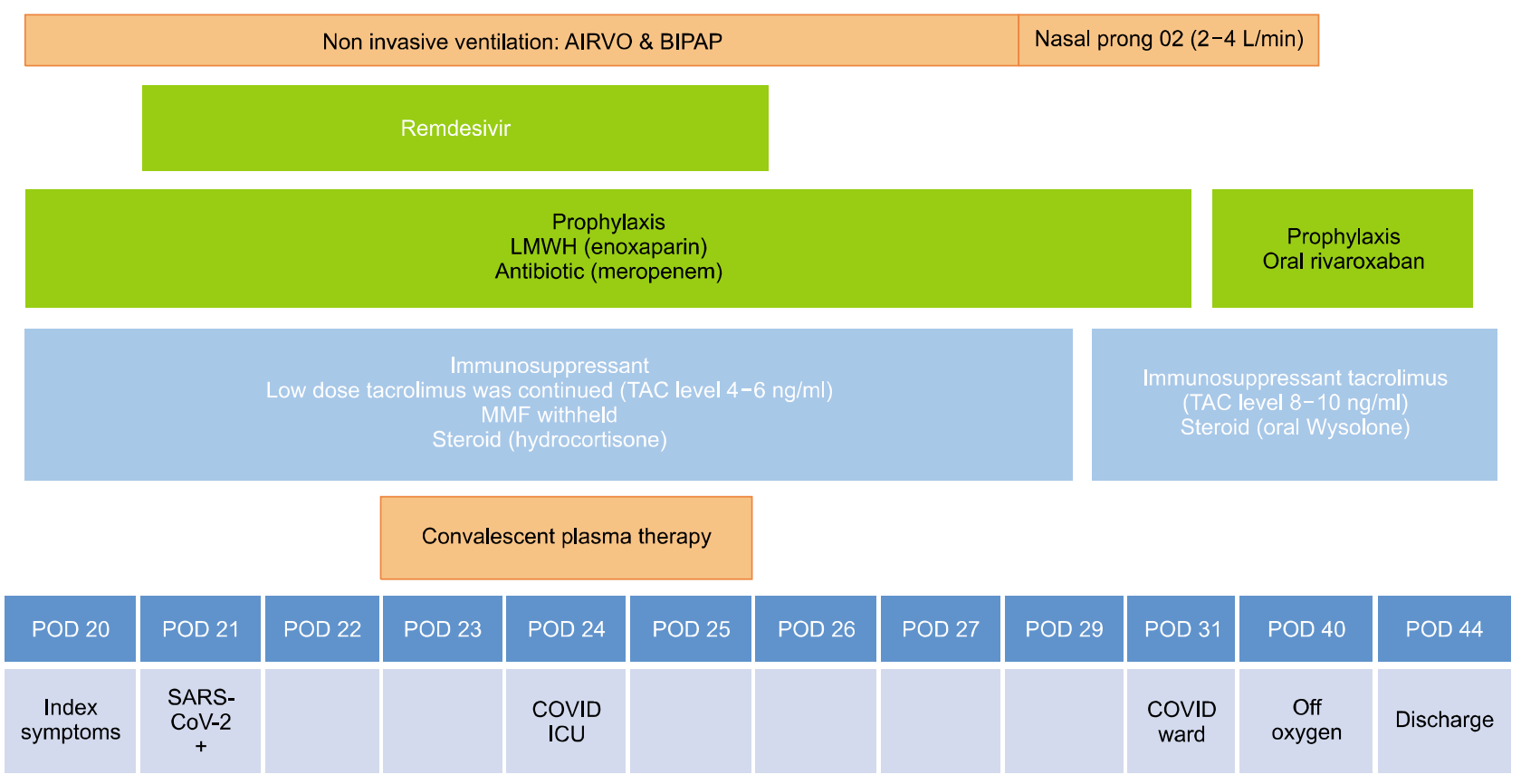

Fig. 2. Clinical course and management timeline during severe COVID-19 pneumonia. 


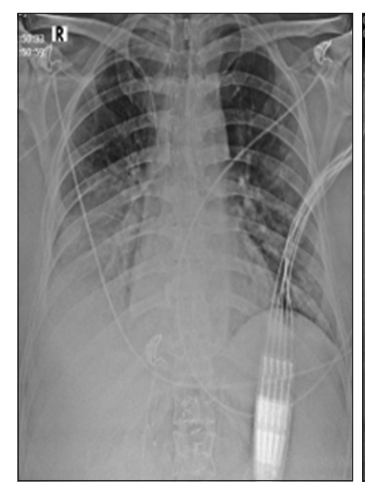

Day 1

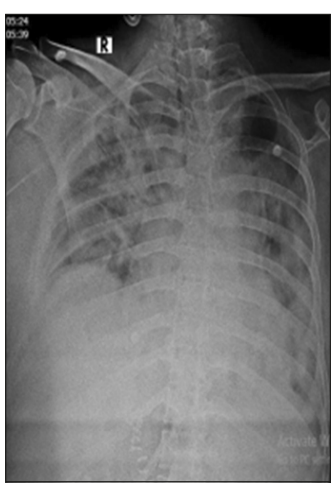

Day 6

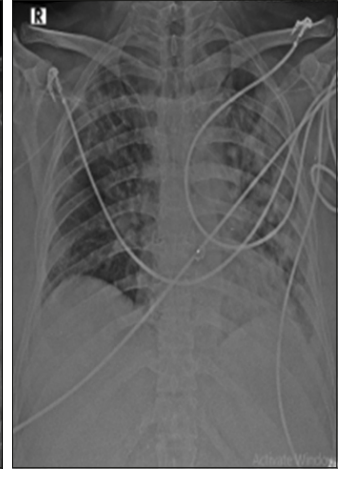

Day 8



Day 16

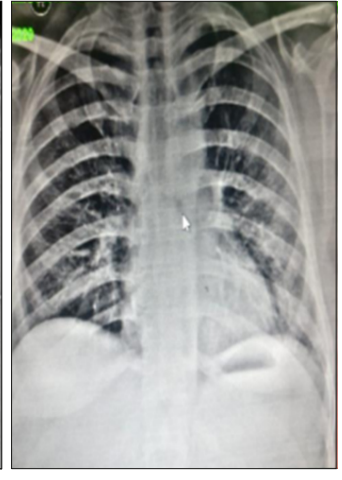

Day 29

Fig. 3. Serial chest X-rays showing gradual resolution of lung opacities.
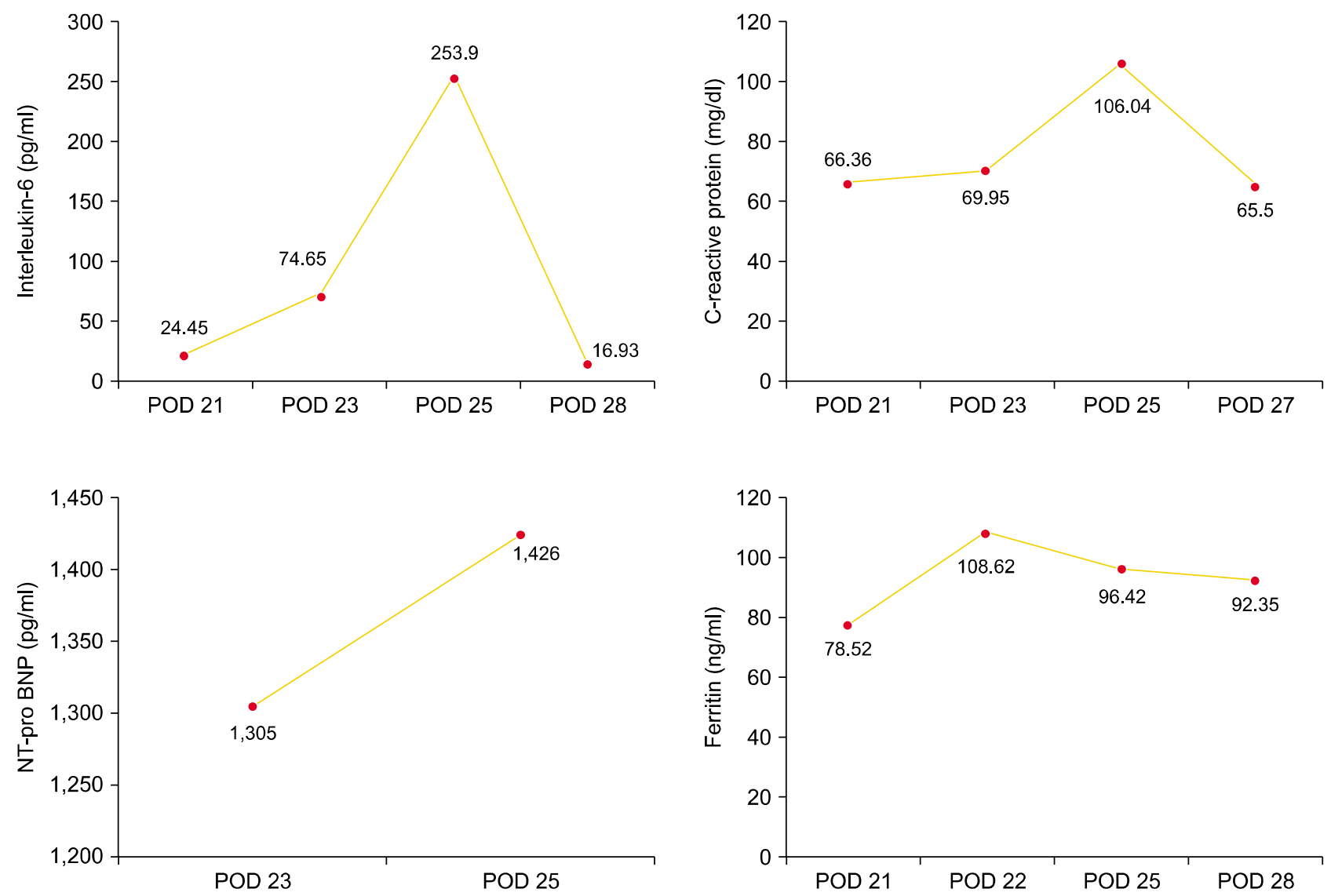

Fig. 4. Changes in the levels of inflammatory markers after treatment with convalescent plasma therapy and remdesivir duo.

with convalescent plasma therapy, our team decided to treat him with fresh convalescent plasma for 2 consecutive days. The $1^{\text {st }}$ aliquot of $200 \mathrm{ml}$ plasma (cut-off index COI-45.8) was transfused on day 4 of fever (POD23) and $2^{\text {nd }}$ aliquot of $230 \mathrm{ml}$ (COI-81.55) was transfused the following day (POD24). The plasma donors were suitable voluntary staff of our hospital who had recently recovered from SARS-CoV-2 infection and been well for over 14 days. The fresh convalescent plasma obtained by apheresis was transfused on the same day of donation. The convalescent plasma was blood type matched but was not checked for donor-specific antibodies. However the rare possibility of convalescent plasma containing HLA antibodies which could result in precipitation of rejection certainly exists.

On day 6 of fever (POD25), despite the above measures 
his IL-6-253.9 pg./ml, CRP-106.04 mg/L, NT-ProBNP$1426 \mathrm{pg} / \mathrm{ml}$ and ferritin-108.62 $\mathrm{ng} / \mathrm{ml}$ continued to rise along with associated worsening of hypoxia (Fig. 4). Our team decided to transfuse an additional $3^{\text {rd }}$ plasma aliquot of $200 \mathrm{ml}$ (COI 93.53). All the three plasma aliquots were obtained from different donors with $\operatorname{IgG}$ antibody titres of more than 1:1000 ( $>6.5$ arbitrary unit/ml correspond to an IgG antibody titre of approximately $>1: 320){ }^{7}$ The further deterioration of his condition was halted with no need for endotracheal intubation. He showed good recovery and subsequent inflammatory markers improved (Fig. 4). On $20^{\text {th }}$ day from index symptoms (POD40) he was off oxygen therapy. The absolute lymphocyte count increased to $1.42 \times 10^{3}$ per microliter and a gradual radiological resolution of the lung opacities was seen on serial chest x-rays (Fig. 3). The aminotransferases and total bilirubin continued to show progressive improvement (Fig. 1). Despite satisfactory clinical improvement, repeat nasopharyngeal swabs for COVID-19 RT-PCR done thrice (day 10, 15 and 22 from index fever) continued to remain positive. As per patient's request to be in home quarantine, he was discharged on $6^{\text {th }}$ August 2020 . He is doing well presently and is being followed up telephonically.

\section{DISCUSSION}

In view of the long persisting COVID-19 pandemic and the clinical worsening of patients awaiting liver transplant, our unit decided to restart the transplant services. We followed the national transplant society guidelines to resume our transplant services after a layover of two months (March, April). ${ }^{2}$ To restrict the possibility of nosocomial COVID-19 transmission through mass contact our transplant unit consisting of surgeons, anesthesiologists and intensive care staffs were segregated and worked in alternate seven day work schedule. The whole team was tested for COVID-19 at the resumption of transplant program. Those who were symptomatic or had contact with high risk COVID-19 patients were quarantined for 14 days and could resume duty only after negative RT-PCR. A dedicated Infection care nurse (ICN) was assigned for monitoring and contact tracing to ensure the safety of our transplant unit. As our patient required multiple hospital visits for variceal bleeds during this time of national lockdown and was awaiting liver transplantation for a long time, we performed living donor liver transplantation on him.

After undergoing an uneventful surgery, he developed clinical acute rejection in the $2^{\text {nd }}$ postoperative week which was treated with methylprednisolone pulse therapy. Towards the end of the third postoperative week he contracted severe COVID-19 pneumonia with impending respiratory failure.

He was switched from oral prednisolone to intravenous hydrocortisone to ameliorate the cytokine release storm (CRS). ${ }^{8}$ Moreover, as he had just recovered from acute rejection, we continued to give him tacrolimus in low dose. Tacrolimus being a lymphocyte inhibitor, can be safely continued in solid organ transplant recipients counterbalancing the CRS with an added advantage of having in vitro antiviral properties. ${ }^{3,9}$ The anti-metabolite MMF was discontinued keeping in consensus with the universal agreement regarding its withdrawal in post-transplant management of severe COVID-19 infection. ${ }^{3}$

We used low molecular weight heparin (LMWH) prophylactically to prevent thromboembolic episodes in our patient. As COVID-19 infection can cause coagulopathies with the involvement of venous, arterial and microcirculatory systems, there might be an increased risk of hepatic artery and portal vein thrombosis in early posttransplant period, the use of anticoagulants have now become a standard clinical practice. ${ }^{10}$

To treat his COVID-19 pneumonia we started him on the potent broad-spectrum antiviral drug remdesivir (RNA polymerases inhibitor). Remdesivir has minimal interactions with immunosuppressant tacrolimus, hence it was preferred over the other antiviral drug lopinavir/ritonavir (protease inhibitor) although remdesivir can cause transaminitis. In a study by Grein et al on compassionate use of remdesivir in 61 covid-19 patients, of the four patients who discontinued remdesivir only two of them had transaminitis as the cause. ${ }^{11}$ As COVID-19 illness also can cause liver injury, to distinguish the cause of transaminitis due to remdesivir or COVID-19 virus may become challenging at times. In our recipient bilirubin and aminotransferase levels during remdesivir administration did not show an increase.

Despite remdesivir and other supportive measures his hypoxia continued to worsen with impending need for tracheal intubation. We contemplated the use of tocilizumab 
(IL-6 inhibitor) as it has shown to ameliorate CRS. Recently it has been used by another centre to treat a COVID-19 pneumonia infected liver transplant recipient. ${ }^{6}$ Elucidating the safety profile of tocilizumab, the drug company stated that it could cause transaminitis with a rare risk of liver failure requiring liver transplant. ${ }^{12}$ Also tocilizumab being an IL-6 inhibitor may interfere with early graft regeneration as IL-6 plays an important role in liver regeneration. ${ }^{13}$ In view of our patient having thrombocytopaenia with recovering transaminitis and the fear of potential hepatotoxicity, we decided against the use of tocilizumab and considered the use of other available immunotherapies.

We had to make a choice between using intravenous immunoglobins or CPT in our patient. Intravenous immunoglobulins are pooled human plasma which lack the specific antibodies against COVID-19 virus. ${ }^{14}$ CPT has multipronged antiviral immunomodulatory effects-direct neutralization and entry of virus into host cells, antibody dependent cellular cytotoxicity and phagocytosis, complement action and other passenger proteins such as anti-inflammatory cytokines, defensin, pentraxins and the undefined protein from convalescent plasma donors. ${ }^{15}$ Convalescent plasma has been successfully used to treat infectious epidemic outbreaks for patients with SARS (severe acute respiratory syndrome), MERS (Middle East respiratory syndrome), and 2009 H1N1 influenza viruses. ${ }^{16}$ The CPT has been shown to reduce mortality rate and length of hospitalization from Wuhan. ${ }^{17}$ The literature is not clear on the dosage and duration of CPT. We transfused two aliquots of convalescent plasma in our recipient however as he did not show much improvement an additional third aliquot was given to which he responded well. $^{7}$

Though the use of plasma therapy in solid organ transplant is anecdotal, CPT with no potential interactions with immunosuppressants and not affecting hepatic and renal functions will form an important armamentarium in the management of COVID-19 illness in SOT recipients. ${ }^{18}$ Preliminary reports have suggested that remdesivir as a sole antiviral may not be sufficient to prevent CRS. ${ }^{19}$ Hence we used the combination of CPT and remdesivir which may have accelerated the virus clearance thereby inhibiting conflagration of CRS as seen by a considerable improvement in his respiratory symptoms, fall in in- flammatory markers and slow but gradual resolution of lung opacities. On literature search, we did not come across the use of this combination in the treatment of COVID-19 pneumonia in liver transplant recipients.

As our centre did not have the facility to measure viral RNA levels for assessment of response we depended on the clinical, inflammatory markers and chest x-rays. The absolute lymphocyte count being below the normal range in the early post-operative period did not help us in the prediction of disease severity. RT-PCR SARS-CoV-2 remained positive at the time discharge making him an asymptomatic shedder. ${ }^{20}$

\section{CONCLUSION}

We report the successful use of Convalescent Plasma Therapy and remdesivir in the management of critically ill COVID-19 pneumonia in post-operative liver transplant setting. The inflammatory markers IL-6, NT pro-BNP and CRP can be used for monitoring CPT response and for determining the additional requirement of convalescent plasma. As lymphocytopenia takes time to recover in the early liver transplant period, it may not be a suitable parameter to assess the severity of COVID-19 pneumonia. The CPT and remdesivir duo can prove to be a perfect combination to salvage liver transplant recipients with severe COVID-19 pneumonia.

\section{ACKNOWLEDGEMENTS}

The Authors would like to specially thank Dr. Angelynn Singh for proofreading the manuscript.

\section{CONFLICT OF INTEREST}

The authors of this manuscript have no conflicts of interest to disclose.

\section{ORCID}

Imtiakum Jamir: https://orcid.org/0000-0003-2217-1372

Pankaj Lohia: https://orcid.org/0000-0002-9277-3822

Rajesh Kumar Pande:

https://orcid.org/0000-0002-0149-727X

Rasika Setia: https://orcid.org/0000-0002-1187-6871 


\author{
Amit Kumar Singhal: \\ https://orcid.org/0000-0002-2746-533X \\ Abhideep Chaudhary: \\ https://orcid.org/0000-0003-4817-4336
}

\section{AUTHOR CONTRIBUTIONS}

Conceptualization: AC, IJ. Data curation: IJ, PL, RS, RKP. Formal analysis: IJ, PL, AC. Visualization: IJ, AC. Writing - original draft: IJ, PL. Writing - review \& editing: IJ, AC, AKS.

\section{REFERENCES}

1. World Health Organization (WHO). WHO coronavirus disease (COVID-19) dashboard. Geneva: WHO; 2020 [cited 2020 Jul 15]. Available from: https://covid19.who.int/table.

2. Saigal S, Gupta S, Sudhindran S, Goyal N, Rastogi A, Jacob $\mathrm{M}$, et al. Liver transplantation and COVID-19 (Coronavirus) infection: guidelines of the liver transplant Society of India (LTSI). Hepatol Int 2020;14:429-431.

3. Fix OK, Hameed B, Fontana RJ, Kwok RM, McGuire BM, Mulligan DC, et al. Clinical best practice advice for hepatology and liver transplant providers during the COVID-19 pandemic: AASLD expert panel consensus statement. Hepatology 2020;72: 287-304.

4. Qin J, Wang $\mathrm{H}$, Qin $\mathrm{X}$, Zhang $\mathrm{P}$, Zhu $\mathrm{L}$, Cai $\mathrm{J}$, et al. Perioperative presentation of COVID-19 disease in a liver transplant recipient. Hepatology 2020. doi: 10.1002/hep.31257. [in press]

5. Pereira MR, Mohan S, Cohen DJ, Husain SA, Dube GK, Ratner LE, et al. COVID-19 in solid organ transplant recipients: initial report from the US epicenter. Am J Transplant 2020;20:18001808.

6. Hammami MB, Garibaldi B, Shah P, Liu G, Jain T, Chen PH, et al. Clinical course of COVID-19 in a liver transplant recipient on hemodialysis and response to tocilizumab therapy: a case report. Am J Transplant 2020;20:2254-2259.

7. Shen C, Wang Z, Zhao F, Yang Y, Li J, Yuan J, et al. Treatment of 5 critically ill patients with COVID-19 with convalescent plasma. JAMA 2020;323:1582-1589.
8. RECOVERY Collaborative Group, Horby P, Lim WS, Emberson JR, Mafham M, Bell JL, et al. Dexamethasone in hospitalized patients with COVID-19 - preliminary report. N Engl J Med 2020. doi: 10.1056/NEJMoa2021436. [in press]

9. Tanaka Y, Sato Y, Sasaki T. Suppression of coronavirus replication by cyclophilin inhibitors. Viruses 2013;5:1250-1260.

10. Bikdeli B, Madhavan MV, Jimenez D, Chuich T, Dreyfus I, Driggin E, et al. COVID-19 and thrombotic or thromboembolic disease: implications for prevention, antithrombotic therapy, and follow-up: JACC state-of-the-art review. J Am Coll Cardiol 2020;75:2950-2973.

11. Grein J, Ohmagari N, Shin D, Diaz G, Asperges E, Castagna A, et al. Compassionate use of remdesivir for patients with severe COVID-19. N Engl J Med 2020;382:2327-2336.

12. Genentech Medical. Serious risk with use of ACTEMRA ${ }^{\circledR}$ (tocilizumab). South San Francisco: Genentech; 2019 [cited 2020 Jul 15]. Available from: https://www.gene.com/download/pdf/ Actemra_DHCP_important-drug-warning_06-19-19.pdf.

13. Schmidt-Arras D, Rose-John S. IL-6 pathway in the liver: from physiopathology to therapy. J Hepatol 2016;64:1403-1415.

14. Liu B, Wang Y, Zhao Y, Shi H, Zeng F, Chen Z. Successful treatment of severe COVID-19 pneumonia in a liver transplant recipient. Am J Transplant 2020;20:1891-1895.

15. Psaltopoulou T, Sergentanis TN, Pappa V, Politou M, Terpos E, Tsiodras S, et al. The emerging role of convalescent plasma in the treatment of COVID-19. Hemasphere 2020;4:e409.

16. Salazar E, Perez KK, Ashraf M, Chen J, Castillo B, Christensen PA, et al. Treatment of coronavirus disease 2019 (COVID-19) patients with convalescent plasma. Am J Pathol 2020;190:16801690

17. Ye M, Fu D, Ren Y, Wang F, Wang D, Zhang F, et al. Treatment with convalescent plasma for COVID-19 patients in Wuhan, China. J Med Virol 2020. doi: 10.1002/jmv.25882. [in press]

18. Jiang J, Miao Y, Zhao Y, Lu X, Zhou P, Zhou X, et al. Convalescent plasma therapy: helpful treatment of COVID-19 in a kidney transplant recipient presenting with serve clinical manifestation and complex complications. Clin Transplant 2020. doi: 10.1111/ctr.14025. [in press]

19. Beigel JH, Tomashek KM, Dodd LE, Mehta AK, Zingman BS, Kalil AC, et al. Remdesivir for the treatment of COVID-19 final report. N Engl J Med 2020. doi: 10.1056/NEJMoa2007764. [in press]

20. Wölfel R, Corman VM, Guggemos W, Seilmaier M, Zange S, Müller MA, et al. Virological assessment of hospitalized patients with COVID-2019. Nature 2020;581:465-469. 